\title{
fabricación económica de cemento a partir de crudos descarbonatados
}

(Wirtschaftliches Zementbrennen aus vorentsăuertem Rohmehl)

H. EIGEN

De: «Tonindustrie-Zeitung und Keramische Rundschaux, vol. 80, núm. 19-20, octubre 1956, pág. 334

En la cocción de clinker de cemento, empleando como materias primas sustanctas previamente descarbonatadas (cal de desecho, escorias de horno alto, carburo cálcico húmedo, etc.), no se habia podido reducir el consumo de calor por debajo de $780 \mathrm{kcal} / \mathrm{kg}$ de clínker, aunque el consumo teórico es del orden de $220 \mathrm{kcal} / \mathrm{kg}$ de clínker. Con este motivo el autor se ha decidido a investigar la termofísica de la cocción del cemento, en el caso de utilizar materias primas descarbonatadas.

En este trabajo de Eigen se presenta la cuestión en sus dos aspectos, teórico y práctico, que, a continuación, vamos a presentar de una forma concisa.

Los cálculos teóricos ponen de maniflesto que el consumo de calor por $\mathrm{kg}$ de clínker pueden reducirse tanto más cuanto menor sea el contenido en $\mathrm{CO}_{3}$ de los crudos. Para contenidos inferiores a un $10 \%$ de $\mathrm{CO}_{2}$, el calor de reacción se hace positivo, es decir, el proceso es exotérmico. 
Vemos, pues, que empleando materias primas adecuadas puede lograrse una reducción fundamental del consumo de calor por $\mathrm{kg}$ de clinker. Ahora bien, si se desea que esta reducción sea lo más efectiva posible, es preciso no olvidarse de otros puntos, también importantes, como son la recuperactón del calor sensible, que se pierde con el clinker, y los gases de escape, que salen del horno.

A la vista de estas consideraciones, el autor presenta un nuevo sistema para realizar la cocción del clínker partiendo de crudos descarbonatados. El nuevo sistema queda representado en la, flgura 1. El crudo, descarbonatado (cal de desecho, arcilla y cuarzo), perfectamente molido y homogeneizado, penetra, por el tubo 1, en el cambiador de calor 2, del tipo de suspensión en gases; en este cambiador se calientan los crudos, y pasan, por el tubo 3 , al pequeño horno de sinterización 4. El clinker producido se enfría, rápida e intensamente, en el enfriador tubular 5, que gira a gran velocidad. La mayor parte del aire caliente, procedente del enfriamiento

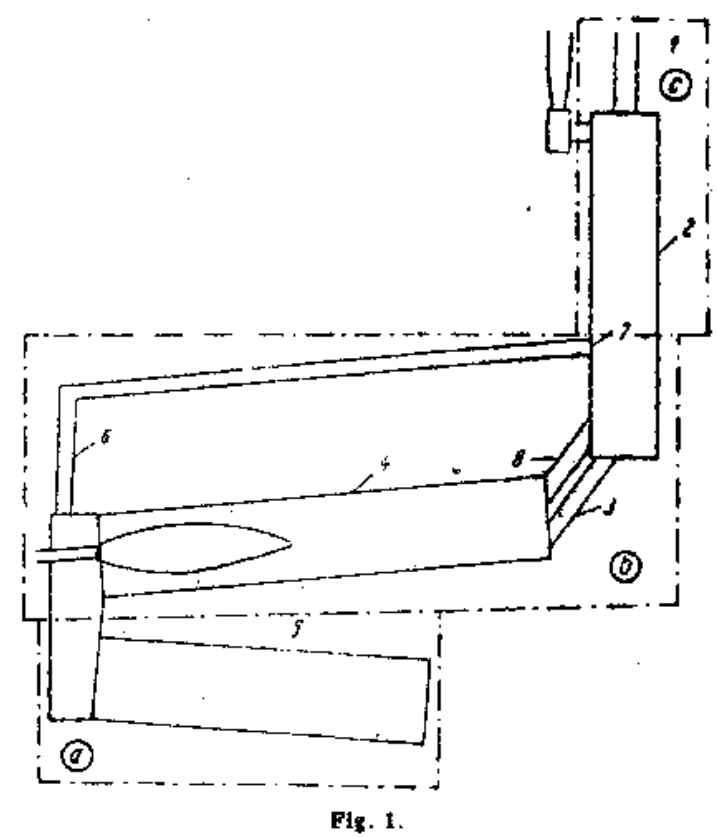

del clínker, se conduce por un tubo 6, perfectamente aislado, al precalentador, penetrando por 7; los gases de escape, procedentes del horno, que han penetrado en el precalentador por el tubo 8, se enfrian, en la parte inferior del precalentador, a la temperatura del alre procedente del enfriador. Con el fin de reducir, antes de la entrada de los gases de escape en el cambiador de calor, la diferencia de temperatura entre dichos gases y el crudo, la zona de entrada del horno rotatorio está revestida con ladrillos de bolslllo.

Para realizar el estudio termofísico del sistema descrito, conviene dividirlo en tres partes (separadas por líneas punteadas), que comprenden:

a) Enfriador.

b) Horno rotatorio, conducción 6 y parte inferior del precalentador.

c) Precalentador (sin la parte inferior). 
Puesto que el cambiador de calor trabaja con una diferencia de temperatura de $200^{\circ} \mathrm{C}$ entre los gases de escape y el material sólido, la temperatura del crudo en el punto 7 es, aproximadamente, de $750^{\circ}-200^{\circ} \mathrm{C}=550^{\circ} \mathrm{C}$.

Los balances térmicos, que se pueden establecer, son los siguientes:

TA B L A I

I,-Consumo total de calor por kg de clínker.

1. Pérdida por las paredes del enfriador.

2. Pérdida por las paredes del horno rotatorio.

keal/kg clfnker

3. Pérdida por las paredes del precalentador.

4. Pérdtda de calor sensíble del clinker.

5. Calor de deshidratación.

6. Calor de vaporización del agua de hidratación.

7. Calor sensible de los gases de escape del precalentador.

8. Calor de formación del clínker (exotérmico).

TOTAI

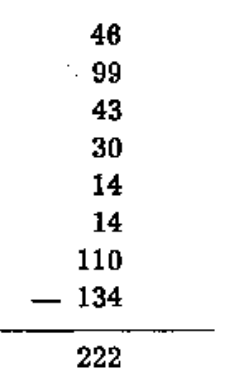

\section{T A B L A I I}

II.-Balance têrmico del enfriador tubular.

1. Calor que entra

a) Caior sensible del clínker: $1,0 \times 1.350^{\circ} \mathrm{C} \times 0,257=$

keal/kg ellnker

347

2. Calor que sale

a) Calor sensible del aire de enfriamiento: $1,1 \mathrm{~m}^{3}(\mathrm{~N}) \times 750^{\circ} \mathrm{C} \times 0,3285=$

b) Pérdida por las paredes del enfriador.

c) Pérdida de calor sensible del clínker.

TOTAL

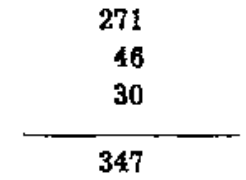

\section{TA B L A I I I}

III.-Balance térmico del horno rotatorio.

1. Calor que entra

a) Potencia calorífica del carbón.

kcal/kg clinker

b) Calor de formación del clínker (exotérmico).

b) Calor de formaclón del clinker (exotermico).

134

a) Calor de los crudos: $1,0 \times 550^{\circ} \mathrm{C} \times 0,220=$

e) Calor sensible del polvo que recircula $(25 \%$ de d) $=$

2. Calor que sale.

$$
\text { TOTAz }
$$

a) Calor sensible del clínker: $1,0 \times 1.350^{\circ} \mathrm{C} \times 0,257=$

b) Pérdida por las paredes del horno rotatorio.

c) Gases de combustión: $0,250 \mathrm{~m}^{3}(\mathrm{~N}) \times 750^{\prime \prime} \mathrm{C} \times 0,365=$

d) Calor sensible del polvo que recircula: $0,25 \times 750^{\prime \prime} \mathrm{C} \times 0,229=$

e) Calor sensible del aire de enfriamiento: $0,896 \mathrm{~m}^{7}(\mathrm{~N}) \times 750^{\circ} \mathrm{C} \times 0,3285=$

TOTAL 
IV.-Balance térmico del precalentador.

1. Calor que entra

kcal/kq clínket

a) Gases de combustión: $0,250 \mathrm{~m}^{3}(\mathrm{~N}) \times 750^{\circ} \mathrm{C} \times 0,365=$

68

b) Calor sensible del polvo que recircula: $0,25 \mathrm{~kg} \times 750^{\circ} \mathrm{C} \times 0,229=$

43

c) Calor sensible del aire de enfriamiento: $0,896 \mathrm{~m}^{3}(\mathrm{~N}) \times 750^{\circ} \mathrm{C} \times 0,3285=$

TOTAL

332

2. Calor que sale

a) Calor sensible de los crudos: $1,0 \times 550^{\circ} \mathrm{C} \times 0,220=$

121

b) Calor sensible del polvo que recircula: $0,25 \times 550^{\circ} \mathrm{C} \times 0,220=$

30

c) Caior de deshidratación.

14

d) Calor de vaporización del agua de hidratación.

14

e) Pérdida por las paredes del precalentador.

43

f) Pérdida de calor sensible en los gases de escape.

110

$\therefore$ Total

332

Para la mejor comprensión de las tablas anterlores, consideramos necesario presentar algunas observaciones aclaratorias.

En la tabla If, al elegir $1,1 \mathrm{~m}^{2}(\mathrm{~N})$ de aire de enfriamiento, su temperatura queda determinada, siendo precisamente $750^{\circ} \mathrm{C}$ (si hubiéramos tomado $0,9 \mathrm{~m}^{3}(\mathrm{~N})$, ia temperatura alcanzada por el aire habría sido de $900^{\circ} \mathrm{C}$ )

Con respecto a la tabla III, hemos de indicar que se ha admitido que el polvo que recircula constituye el $25 \%$ del clínker producido. La cantidad teórica de aire de combustión es 222. $.0,0010816=0,240 \mathrm{~m}^{2}(\mathrm{~N}) / \mathrm{kg}$ de clínker, de los cuales $0,036 \mathrm{~m}^{2}(\mathrm{~N})$ constituyen el aire primario $\mathrm{y}$ $0,204 \mathrm{~m}^{3}(\mathrm{~N})$ el aire secundario. Del aire caliente procedente del enfriador, $1,100 \mathrm{~m}^{3}(\mathrm{~N})$, se dispone de $0,896 \mathrm{~m}^{3}(\mathrm{~N})$ como exceso. Puesto que la combustión del carbón pulverizado debe llevarse a cabo con un exceso de atre, será preciso introducir una parte de aquel exceso de aire en el horno; se introducen $0,109 \mathrm{~m}^{3}(\mathrm{~N}) / \mathrm{kg}$ de clinker, con lo cual resulta que la combustión tiene lugar con un exceso de aire del $80 \%$. Además, quedan $0,706 \mathrm{~m}^{\mathrm{3}}(\mathrm{N})$ de aire caliente $\left(750^{\circ} \mathrm{C}\right)$ que se llevan al precalentador.

El balance térmico indicado en la tabla IV se refiere sólo a la parte de precalentador situada por encima de la entrada 7 del tubo 6; en dicha zona, el crudo se callenta hasta $550^{\circ} \mathrm{C}$. En esta tabla puede observarse, claramente, que los gases de combustión propiamente dichos sólo introducen $68 \mathrm{kcal} / \mathrm{kg}$ clinker, es decir, el $20 \%$ del calor total que se necesita en el precalentador.

La pérdida de calor sensible de los gases sensibles es de $110 \mathrm{kcal} / \mathrm{kg}$ clínker. El total de los gases de escape, húmedos, se compone de:

Gases de combustión, húmedos.

Vapor procedente del agua de hidratación.

Aire.
$0,250 \mathrm{~m}^{\mathrm{i}}(\mathrm{N}) / \mathrm{kg}$ clínker

$0,030 \mathrm{~m}^{3}(\mathrm{~N}) / \mathrm{kg}$ clínker $0,896 \mathrm{~m}^{\mathrm{9}}(\mathrm{N}) / \mathrm{kg}$ clínker

TOTAL 
En comparación con los hornos rotatorlos corrientes, la cantidad de gases de escape es, en este caso, extraordinariamente pequeña. La temperatura de estos gases es de $282^{\circ} \mathrm{C}$.

Queda, de esta forma, tratado a fondo el tema. Queda, no obstante, todavia un punto interesante. Se trata del peligro que puede existir de que se produzca Ia hidratación y recarbonatación de la cal libre. Sin embargo, puesto que el gas del precalentador se compone de un $76 \%$ de aire y de $4 \%$ (en volumen) de vapor de agua, el peligro de hidratación es extraordinariamente pequeño. Lo mismo podemos decir para la recarbonatación, pues que dícho gas sólo contiene un $4 \%$ de $\mathrm{CO}_{2}$. La permanencla del crudo en el cambiador de calor es de quince segundos; de modo que en la zona de hidratación y recarbonatación sólo permanece cinco segundos. Vemos, pues, que por todos estos motivos queda extraordinariamente dificultada la reacción de las moléculas de agua. y de carbónico con la cal libre.

Hemos de Indicar, como nota final, que en el caso de emplear escorias pulverizadas el consumo total de calor seria de 560-600 kcal/kg clínker.

S. F. S. 